\title{
A Review of Quality Criteria Supporting Supplier Selection
}

\author{
Mohammad Abdolshah \\ Engineering Faculty, Islamic Azad University, Semnan Branch, Semnan 35136-93688, Iran \\ Correspondence should be addressed to Mohammad Abdolshah; abdolshah@gmail.com
}

Received 31 December 2012; Accepted 28 April 2013

Academic Editor: Shey-Huei Sheu

Copyright (C) 2013 Mohammad Abdolshah. This is an open access article distributed under the Creative Commons Attribution License, which permits unrestricted use, distribution, and reproduction in any medium, provided the original work is properly cited.

This paper presents a review of decision criteria reported in the literature for supporting the supplier selection process. The review is based on an extensive search in the academic literature. After a literature review of decision criteria, we discuss the most important criteria: quality. Then different methods and factors for assessing the quality of supplier are discussed. Results showed that all methods and factors mentioned in this paper are not appropriate tools for quality evaluation. Moreover, we propose a novel method (using loss functions) in order to assess the quality of suppliers.

\section{Introduction}

Nowadays companies hope to establish a longer-term working relationship with the suppliers. Therefore, supplier selection is one of the main parts of decisions in supply chain management. Because there are many suppliers with many criteria, so it is impossible to find the best way to evaluate and select suppliers. Therefore, in studies, scholars have used different methods, variables, criteria, and factors in order to select the suppliers.

Evaluation of suppliers is a process that leads companies to select their desired suppliers. This process has two main aims, which are to reduce all costs of purchasing and to increase the overall value of the purchasing [1]. Regarding to the costs of evaluating the suppliers (such as time and travel budget), companies basically evaluate those suppliers that have a good chance of qualifying for purchasing from them. In this process, formally, companies send expert teams to the supplier site, and with evaluating different criteria and factors, they will do an in-depth evaluation.

There are different steps that must be done in the process of supplier evaluation and selection [1]. As it is shown in Figure 1, in order to evaluate and select the suppliers, companies must identify some important things such as methodologies, criteria, and problems (strategies).
This paper focused on the literature review of criteria for supplier evaluation and especially the criteria related to the quality evaluation of suppliers.

\section{Decision Criteria Formulation}

Regarding to multicriteria decision-making concept of supplier selection problems, one of the main parts of this process is to define related factors and criteria. There are many criteria such as price, quality, and process capability and on time delivery, which can affect selecting the proper supplier. There are many studies since the 1960s about factors, which affect supplier selection. Roa and Kiser [2], Ellram [3], and Stamm and Golhar [4] mentioned 60, 18, and 13 criteria for supplier selection, respectively. Weber at al. [5] reviewed 47 articles in which more than one criterion was considered in supplier selection models. One crucial study, which was done by Dickson [6], identified 23 different criteria evaluated in supplier selection.

This study was on the base of a questionnaire that was sent to 273 purchasing agents and managers from the United States and Canada. Their survey showed that price, delivery, and quality are three main factors, which are important for them. Weber et al. [5] also did a similar survey and concluded that price, delivery, quality, production capacity, and localization are the most important criteria. 


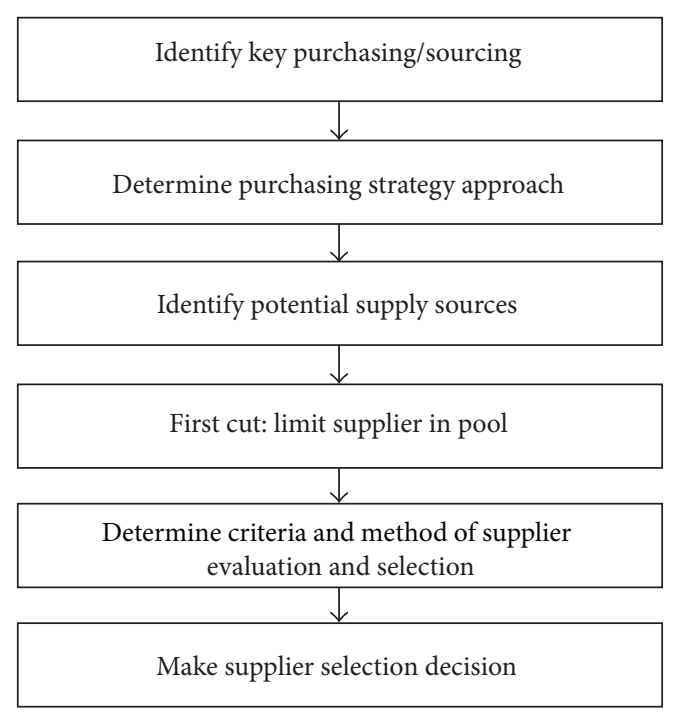

FIgURE 1: Supplier evaluation and selection process [1].

Although the evolution of the industrial environment modified the degrees of the relative importance of supplier selection criteria since the 1960 s, the 23 ones presented by Dickson [6] still cover the majority of those presented in the literature until today. Ha and Krishnan [8] and Aissaoui et al. [9] investigated 31 main criteria which were related to supplier selection in the literature since 1966. In this study, we added some new studies and summarized them in Table 2: A: Dickson [6]; B: Wind et al. [10]; C: Lehmann and haughnessy [11]; D: Perreault and Russ [12]; E: Abratt [13]; F: Billesbach et al. [14]; G: Weber et al. [5]; I: Min and Galle [15]; J: Stavropolous [16]; K: Pi and Low [17]; L: Pi and Low [18], M: Teeravaraprug [19]; N: Sanayei et al. [20]; O: Parthiban et al. [21]; P: Peng [22]; Q: Bilişik et al. [23]; R: Tektas and Aytekin [24]; S: Li [25]; T: Betül et al. [26]; U: Mehralian et al. [27].

\section{Assessing the Quality}

Quality is one of the main criteria for supplier evaluation and supplier selection. As it showed in Table 1, among 23 criteria, quality was the main criterion for supplier evaluation [6]. Holjevac [28] defined quality as follows:

(i) quality refers to the ability of a product or service to consistently meet or exceed customer's expectations;

(ii) quality means getting what you have paid for;

(iii) quality is not something that is adopted as a special feature; instead, it is an integral part of a product or service.

Assessing quality as one of the main factors for supplier selection is so important. In order to assess the quality, there are many factors and methods that can be used. There are a lot of literatures which have been accumulated on the subject of vendor evaluation and selection models, and in order to evaluate quality, most of these models have used rate of rejects $[20,29,30]$, while rate of rejects cannot present the quality appropriately. In a recent study, Lee [31] used yield rate in order to evaluate the quality. In the next chapter, it is mentioned why the rate of rejects or yield rate are not appropriate tools for assessing the quality.

Some scholars integrated some factors in order to evaluate the quality. Teng and Jaramillo [32] integrated continuous improvement programs, quality of customer, support services, certifications, and percentage on time shipment. In another study, Hou and Su [33] defined a quality index with integration of technical and design level, ease of repair, and reliability. Xia and Wu [34] used just technical and design level, and reliability in order to evaluate the quality. These factors also cannot present the core of quality level of products.

Process capability indices are appropriate and suitable indices in order to evaluate the quality, but presenting them as cost are so complicated, so some scholars presented an innovative qualitative method with the integration of process capability indices and other factors.

In the other hand, some scholars have used process capability indices in order to evaluate the quality. Tseng and $\mathrm{Wu}$ [35] considered the problem of selecting the best manufacturing process from some available processes based on the "precision" capability index $C_{p}$ and have proposed a modified likelihood ratio (MLR) selection rule. They prepared some tables of the sample size and of the critical values for selecting the best manufacturing by controlling the probability based on the proposed MLR selection rule. Moreover, in case a nonnormal symmetric distribution, Tseng and $\mathrm{Wu}$ [35] used simulation to examine the robustness of the selection rule. Their results showed that the proposed modified likelihood ratio selection rule is acceptable for nonnormal symmetric process distributions.

Chou [36] developed an approximate method for selecting a better supplier based on one-sided capability indices $C_{p u}$ and $C_{p l}$ when the sample sizes are the same, which deals with comparing two one-sided processes and selects better one with the higher process yield. Pearn et al. [37] investigated the selection power analysis of the method via simulation and process capability. Huang and Lee (1995) proposed a model for selection a subset of processes containing the best supplier from a given set of processes. Under the circumstances, a search for the larger $C_{p m}$ which are used to provide a measure of the process performance is equivalent to a search for the smaller $\gamma^{2}$ [38].

The selection method proposed by Chou [36] utilized some approximating results but provide no indication on how one could further proceed with selecting the better supplier by testing process capability index $C_{p u}$ or $C_{p l}$. Pearn et al. [37] investigated the selection power analysis of the method via simulation. The accuracy analysis provides useful information regarding the sample size required for designated selection power. To render this method practical for in-plant applications, a two-phase selection procedure is developed by Pearn et al. [37] to select the better supplier and examine further the magnitude of the difference between the two suppliers [38].

There are some innovative research with the integration of process capability and other factors in order to select the 
TABLE 1: 23 supplier evaluation criteria [6].

\begin{tabular}{|c|c|c|c|}
\hline Rank & Criteria & Mean rating & Evaluation \\
\hline 1 & Quality & 3.508 & Extreme importance \\
\hline 2 & Delivery & 3.417 & \\
\hline 3 & Performance history & 2.998 & \\
\hline 4 & Warranties and claim policies & 2.849 & \\
\hline 5 & Production facilities and capacity & 2.775 & Considerable importance \\
\hline 6 & Price & 2.758 & \\
\hline 7 & Technical capability & 2.545 & \\
\hline 8 & Financial position & 2.514 & \\
\hline 9 & Procedural compliance & 2.488 & \\
\hline 10 & Communication system & 2.426 & \\
\hline 11 & Reputation and position in industry & 2.412 & \\
\hline 12 & Desire for business & 2.256 & \\
\hline 13 & Management and organization & 2.216 & \\
\hline 14 & Operating controls & 2.211 & \\
\hline 15 & Repair service & 2.187 & Average importance \\
\hline 16 & Attitude & 2.120 & \\
\hline 17 & Impression & 2.054 & \\
\hline 18 & Packaging ability & 2.009 & \\
\hline 19 & Labor relations record & 2.003 & \\
\hline 20 & Geographical location & 1.872 & \\
\hline 21 & Amount of past business & 1.597 & \\
\hline 22 & Training aids & 1.537 & \\
\hline 23 & Reciprocal arrangements & 0.610 & Slight importance \\
\hline
\end{tabular}

best supplier. Linn et al. [7] presented CPC chart for supplier selection problem (Figure 2). The CPC chart integrates the process capability and price information of multiple suppliers and presents them in a single chart. It provides a simple and useful method to consider quality and price simultaneously in the supplier selection process. However, this chart uses $C_{p k}$ index, while we know that this process capability index is not a proper index to evaluate quality.

In order to evaluate supplier, Linn et al. [7] considered some factors such as quality, on-time delivery, price, and service, but the strategy is not clear if the purchase department wants to buy many kinds of materials from one supplier. It means in this case that some other factors must be considered, because purchase department always wants to buy all materials from one or two suppliers, so the shipment cost also will be decreased. Similarly Zhu [39] established a suppliers capability and price information chart (SCPIC) (Figure 3) focused on the case where the specification limits are symmetric about the target for evaluating supplier performance which applies the process incapability index to measure supplier quality performance.

Assessing quality as one of the main factors for supplier selecting is so important. In order to assess the quality there are many factors and methods that can be used. There are a lot of literatures accumulated on the subject of vendor evaluation and selection models, and in order to evaluate quality, most of these models have used rate of rejects $[20,29,30]$, while rate of rejects cannot present the quality appropriately. In a recent study, Lee [31] used yield rate in order to evaluate the quality.

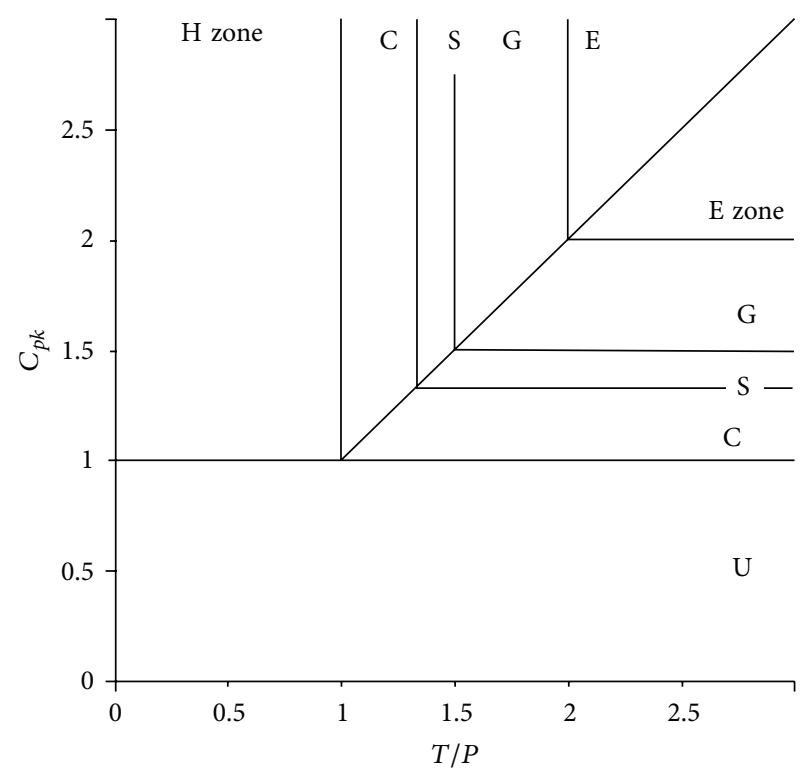

Figure 2: CPC chart [7].

There are few studies about the usage of loss functions in order to selection the suppliers. In these studies, scholars just have used the concepts of loss function in order to weigh the criteria. Pi and Low [17] used Taguchi loss [42] and assumed $3 \%$ defective products as the standard rate of rejects, and the quality could be calculated with Taguchi loss function and 
TABLE 2: Various selection criteria that have emerged in the literature.

\begin{tabular}{|c|c|c|c|c|c|c|c|c|c|c|c|c|c|c|c|c|c|c|c|c|c|}
\hline Selection criteria & A & B & $\mathrm{C}$ & $\mathrm{D}$ & $\mathrm{E}$ & $\mathrm{F}$ & G & $\mathrm{H}$ & $\mathrm{I}$ & $\mathrm{J}$ & $\mathrm{K}$ & $\mathrm{L}$ & $\mathrm{M}$ & $\mathrm{N}$ & $\mathrm{O}$ & $\mathrm{P}$ & Q & $\mathrm{R}$ & $S$ & $\mathrm{~T}$ & $\mathrm{U}$ \\
\hline Price (cost) & $\sqrt{ }$ & $\sqrt{ }$ & $\sqrt{ }$ & $\sqrt{ }$ & $\sqrt{ }$ & $\sqrt{ }$ & $\sqrt{ }$ & & $\sqrt{ }$ & $\sqrt{ }$ & $\sqrt{ }$ & $\sqrt{ }$ & $\sqrt{ }$ & & $\sqrt{ }$ & $\sqrt{ }$ & & & $\sqrt{ }$ & $\sqrt{ }$ & $\sqrt{ }$ \\
\hline Quality & $\sqrt{ }$ & $\sqrt{ }$ & $\sqrt{ }$ & $\sqrt{ }$ & & $\sqrt{ }$ & $\sqrt{ }$ & & $\sqrt{ }$ & & $\sqrt{ }$ & $\sqrt{ }$ & $\sqrt{ }$ & & $\sqrt{ }$ & $\sqrt{ }$ & $\sqrt{ }$ & $\sqrt{ }$ & $\sqrt{ }$ & & $\sqrt{ }$ \\
\hline Delivery & $\sqrt{ }$ & $\sqrt{ }$ & $\sqrt{ }$ & $\sqrt{ }$ & & $\sqrt{ }$ & $\sqrt{ }$ & & $\sqrt{ }$ & & $\sqrt{ }$ & $\sqrt{ }$ & $\sqrt{ }$ & $\sqrt{ }$ & $\sqrt{ }$ & & $\sqrt{ }$ & $\sqrt{ }$ & $\sqrt{ }$ & $\sqrt{ }$ & $\sqrt{ }$ \\
\hline Warranties and claims & $\sqrt{ }$ & & $\sqrt{ }$ & & & & & & & & & & & & & & & & & & \\
\hline After sales service & $\sqrt{ }$ & & $\sqrt{ }$ & & $\sqrt{ }$ & & $\sqrt{ }$ & & & & & $\sqrt{ }$ & & & $\sqrt{ }$ & & & & $\sqrt{ }$ & & \\
\hline Technical support & & & $\sqrt{ }$ & & $\sqrt{ }$ & $\sqrt{ }$ & & & & & & & & & & & & & & & \\
\hline Training aids & $\sqrt{ }$ & & $\sqrt{ }$ & & & & $\sqrt{ }$ & & & & & & & & & & & & & & \\
\hline Attitude & $\sqrt{ }$ & & & & $\sqrt{ }$ & & $\sqrt{ }$ & & & & & & & & & & & & & & \\
\hline Performance history & $\sqrt{ }$ & & & & & & $\sqrt{ }$ & & & & & & & & & & & & & & \\
\hline Financial position & $\sqrt{ }$ & & $\sqrt{ }$ & & & & $\sqrt{ }$ & & & & & & & & & & & $\sqrt{ }$ & & & \\
\hline Geographical location & $\sqrt{ }$ & $\sqrt{ }$ & & $\sqrt{ }$ & & & $\sqrt{ }$ & & & & & & & & & & & & & & \\
\hline Management and organization & $\sqrt{ }$ & & & $\sqrt{ }$ & & & $\sqrt{ }$ & & & & & & & $\sqrt{ }$ & & & & & & $\sqrt{ }$ & \\
\hline Labor relations & $\sqrt{ }$ & & & & & & $\sqrt{ }$ & & & & & & & & $\sqrt{ }$ & & & & & & \\
\hline Communication system & $\sqrt{ }$ & & & & & & $\sqrt{ }$ & & & & & & & & & & $\sqrt{ }$ & & & & \\
\hline Response to customer request & & & $\sqrt{ }$ & & & $\sqrt{ }$ & & & & & & & $\sqrt{ }$ & & & & & & & & \\
\hline E-commerce capability & & & & & & & & $\sqrt{ }$ & $\sqrt{ }$ & $\sqrt{ }$ & & & & & & & & & & & $\sqrt{ }$ \\
\hline JIT capability & & & & & & $\sqrt{ }$ & & $\sqrt{ }$ & & & & & & & & & & & & & \\
\hline Technical capability & $\sqrt{ }$ & $\sqrt{ }$ & & & & & $\sqrt{ }$ & $\sqrt{ }$ & & & & & & & & $\sqrt{ }$ & $\sqrt{ }$ & & & & $\sqrt{ }$ \\
\hline Production facilities and capacity & $\sqrt{ }$ & & & & & & $\sqrt{ }$ & & & & & & & & $\sqrt{ }$ & & & & & $\sqrt{ }$ & \\
\hline Packaging ability & $\sqrt{ }$ & & & & & & $\sqrt{ }$ & & & & & & & & & & & & & & \\
\hline Operational controls & $\sqrt{ }$ & & & & & & $\sqrt{ }$ & & & & & & & & & & & & & & \\
\hline Ease of use & & & $\sqrt{ }$ & & $\sqrt{ }$ & & & & & & & & & & & & & & & & \\
\hline Maintainability & & & $\sqrt{ }$ & & $\sqrt{ }$ & & & & & & & & & & & & & & & & \\
\hline Amount of past business & $\sqrt{ }$ & $\sqrt{ }$ & $\sqrt{ }$ & & & & $\sqrt{ }$ & & & & & & & & & & & & & & \\
\hline Reputation and position in industry & $\sqrt{ }$ & $\sqrt{ }$ & $\sqrt{ }$ & & $\sqrt{ }$ & & $\sqrt{ }$ & & & & & & & $\sqrt{ }$ & & & & & & & $\sqrt{ }$ \\
\hline Reciprocal arrangements & $\sqrt{ }$ & $\sqrt{ }$ & & $\sqrt{ }$ & & & $\sqrt{ }$ & & & & & & & & & & & & & & \\
\hline Impression & $\sqrt{ }$ & & $\sqrt{ }$ & & $\sqrt{ }$ & & $\sqrt{ }$ & & & & & & & & & & & & & & \\
\hline Environmentally friendly products & & & & & & & & & $\sqrt{ }$ & & & & & & $\sqrt{ }$ & & & $\sqrt{ }$ & & & $\sqrt{ }$ \\
\hline Product appearance & & & & & & & & & & $\sqrt{ }$ & & & & & & & & & & & \\
\hline Catalog technology & & & & & & & & & & $\sqrt{ }$ & & & & & & & & & & & \\
\hline Dependability $^{1}$ & & & & & & & & & & & & & $\sqrt{ }$ & $\sqrt{ }$ & & & & & & & \\
\hline Flexibility $^{2}$ & & & & & & & & & & & & & & $\sqrt{ }$ & & & & & & & $\sqrt{ }$ \\
\hline Payment terms & & & & & & & & & & & & & & $\sqrt{ }$ & & & & & & & \\
\hline Productivity & & & & & & & & & & & & & & & $\sqrt{ }$ & $\sqrt{ }$ & $\sqrt{ }$ & & & & \\
\hline Applicable of conceptual Manufacturing & & & & & & & & & & & & & & & $\sqrt{ }$ & & & & & & \\
\hline Manufacturing challenges & & & & & & & & & & & & & & & $\sqrt{ }$ & & & & & & \\
\hline Driving Power & & & & & & & & & & & & & & & $\sqrt{ }$ & & & & & & \\
\hline To match the lead times & & & & & & & & & & & & & & & & & $\sqrt{ }$ & & & & \\
\hline Personnel capability & & & & & & & & & & & & & & & & & $\sqrt{ }$ & & & & \\
\hline To be solution oriented & & & & & & & & & & & & & & & & & $\sqrt{ }$ & & & & \\
\hline Global factors & & & & & & & & & & & & & & & & & & $\sqrt{ }$ & & & \\
\hline Environmental risk & & & & & & & & & & & & & & & & & & & & & $\sqrt{ }$ \\
\hline
\end{tabular}

${ }^{1}$ Dependability refers to the ability to supply items as promised. Dependability sometimes includes delivery due date, delivery accuracy, and delivery completeness.

${ }^{2}$ Ability to change or revise in the production operations.

A: Dickson [6]; B: Wind et al. [10]; C: Lehmann and haughnessy [11]; D: Perreault and Russ [12]; E: Abratt [13]; F: Billesbach et al. [14]; G: Weber et al. [5]; I: Min and Galle [15]; J: Stavropolous [16]; K: Pi and Low [17]; L: Pi and Low [18], M: Teeravaraprug [19]; N: Sanayei et al. [20]; O: Parthiban et al. [21]; P: Peng [22]; Q: Bilişik et al. [23]; R: Tektas and Aytekin [24]; S: Li [25]; T: Betül et al. [26]; U: Mehralian et al. [27]. 


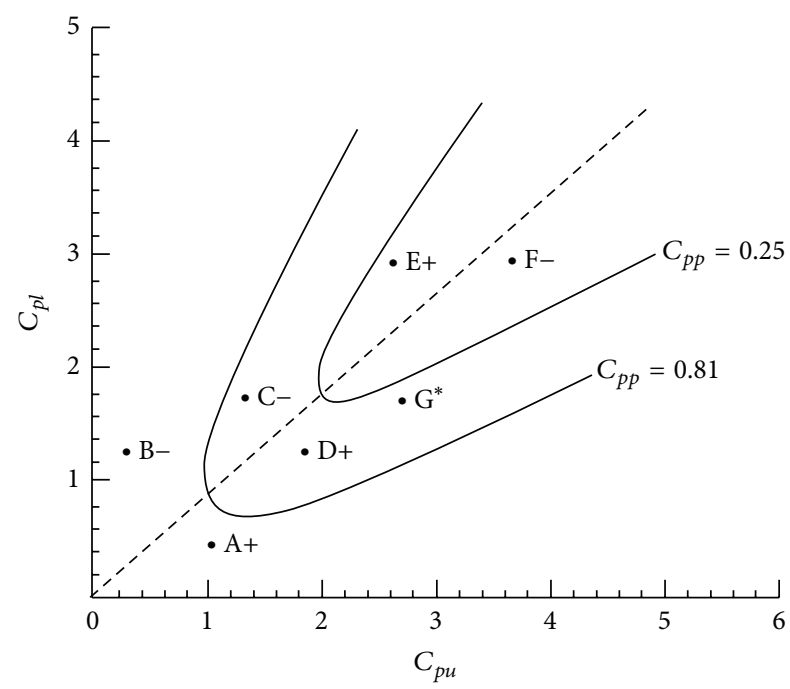

FIGURE 3: Suppliers' capability and price information chart [39].

this target value. In another study, they [18] continued their research and proposed an AHP method in order to select the final supplier.

Teeravaraprug [19] proposed a new model for outsourcing and vendor selection based on Taguchi loss function. In this interesting study loss, the function was used in order to calculate the quality rate, but in its methodology Taguchi loss function was used for just weighting the different rates, and again in order to calculate the quality, just rate of rejects assumed. Summary of the main studies in this area is shown in Table 3.

Regarding to fierce worldwide competition, quality turned to be one of the main factorsdwhich directly affects the supplier selection decision. As stated in the literature review, quality can be assessed by methods categorized in two different groups. The first group consists of qualitative methods such as continuous improvement programs, quality of customer and support services, certifications, technical and design level, capability of handling abnormal quality, and ease of repair. The second group consist of quantitative methods including reliability, rate of rejects, yield rate, process capability indices, and loss functions.

Since qualitative methods can evaluate just one aspect of an organization but cannot evaluate the whole production process, they are not suitable methods for assessing the quality of a process. For example, one product of an organization may have a bad quality, but the recent top manager of the organization has taken the basic decision to implement some continuous improvement programs. Continuous improvement programs help to enhance the quality, but they cannot guarantee the quality of the current products. There are some quality certifications, such as ISO 9000, focused on the quality management in organizations. These quality systems can be chosen in order to assess the quality of an organization, but they cannot be an appropriate representative of the quality of the products. For example, Reimann and Hertz [44] stated that ISO registration does not necessarily mean the following words: (1) good or improving product quality, (2) satisfaction of customer's needs, (3) comparable levels of product quality among registered companies, (4) better quality than nonregistered companies, and (5) good or improving productivity, responsiveness, competitiveness, or workforce development. Moreover, Juran [41] acknowledged that a comprehensive quality system defined by ISO standards has a degree of merit, but the certification alone will not enable companies to attain world-class quality.

Quality of customer and support services is another criterion in order to evaluate the quality of suppliers. This criterion is a sign of implementing customer-based systems in organizations, but customers just with considering this factor cannot assure the quality of the products. Some organizations may show off their responsibility and hide their weak points with a flashy customer and support service.

Technical and design level is another criteria, which is used for assessing the quality in some studies. Technical and design level helps organizations to produce products with better quality, but for multiproduction organization, it is hard to assess whether high technical and design level has an effect on the quality of a specific product or not. Also, in assembly organizations, the technical and design level cannot guarantee the product quality. Since nowadays customers often tend to replace the defective products or defective parts, the product, or one part of it, repairing has missed its position in the term of quality. So the item "ease of repair" is not an appropriate criterion for quality assessment.

Capability of handling abnormal quality products is another qualitative method, which is important but cannot guarantee the quality of products. Nowadays, some new approaches such as zero defects which rely on the zero rates of rejects are emerging, so organizations, instead of focusing on problems of abnormal quality products such as handling of them, focus on low rate of rejects. On the other hand, a supplier can have a bad quality of products, but a good service for handling abnormal quality products.

The second group of quality assessment methods consists of quantitative methods. The quantitative methods also have some weak points. For example, some studies evaluated the reliability of products instead of assessing the quality. Reliability is defined as the probability that a product will successfully perform without any failure, under specified environmental conditions, for a specified period of time [45]. In this definition, there is not a distinction between a product, which its quality specifications are really close to the target, and an accepted product, which its quality performance is far from the target. Ramakrishnan et al. [43] presented an example of solder bump failures in assembly process (Figure 4). They showed a high process capability index, but actually the rate of rejects is high and consequently the reliability is low.

The example of Ramakrishnan et al. [43] showed that process capability indices also have some weak points in order to evaluate the quality of products. Moreover, Perakis and Xekalaki [46] illustrated that process capability indices such as $C_{p}, C_{p k}$, and $C_{p m}$ do not have a direct relationship with the conformance proportion of the process.

Rate of rejects is one of the main methods for assessing the quality. This method selects the supplier with least rate 


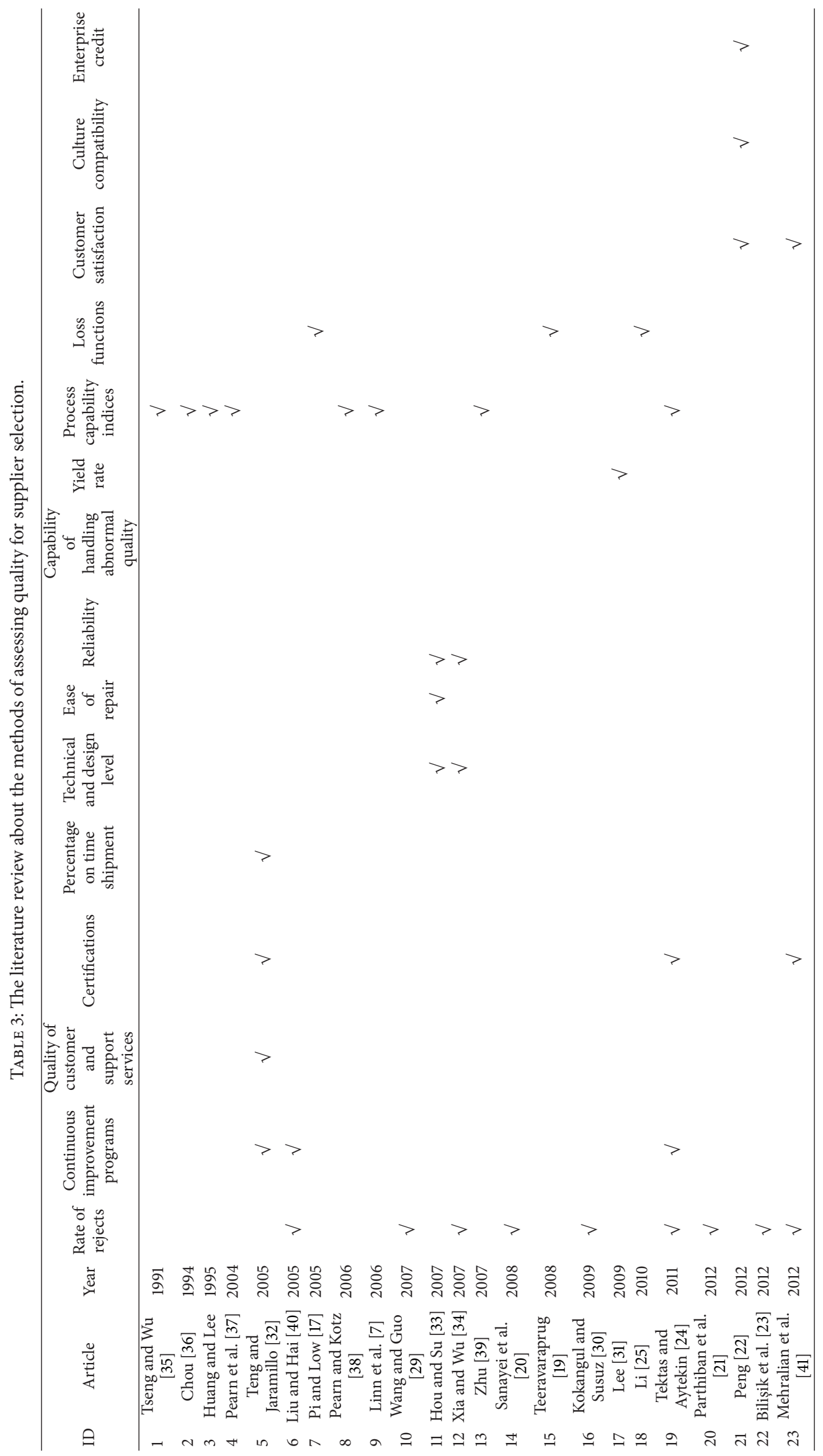




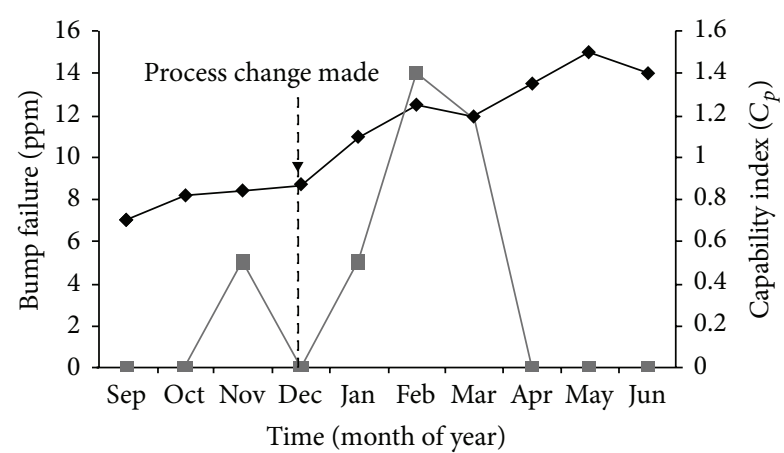

FIgURE 4: An example about relation of process capability index and bump failures (ppm) [43].

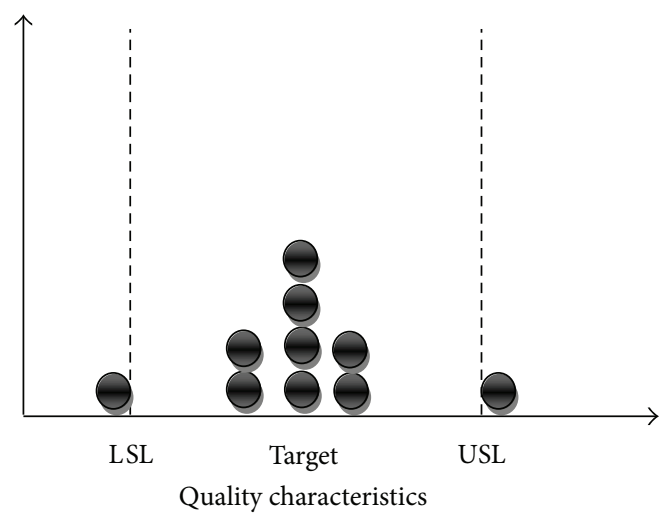

Figure 5: Samples from process A.

of rejects. This is a good quantitative method for assessing the quality, but it cannot be useful in case of similar rate of rejects. For instance, suppose that two samples were selected from suppliers A and B. Each Sample consisted of 10 parts. Suppose that for both samples, eight quality characteristics fall within specification limits (LSL, USL), as stated in Figure 5. Regarding to rate of rejects method, there is no any differences between them because rate of rejects of supplier $\mathrm{A}=$ rate of reject of supplier $\mathrm{B}=0.2$, but Figures 5 and 6 show that there is a significant difference between them and process A has a better quality.

Yield rate is an opposite concept to rate of rejects and behaves the same. Similarly based on Figures 5 and 6 , it is concluded that yield rate of both processes is the same (80\%), but there is a significant difference between them.

On time shipment percentage similarly presents a quality factor, which is indirectly related to the quality of products. On time shipment deals with delivery, and it does not take into account the quality. Finally, in some studies, scholars in order to assess the quality have used the loss functions. Since loss functions take into account all samples and also have a significant relation with loss, they seem to be appropriate and reliable functions for evaluating the quality of suppliers. However, as stated in the literature review, the studies which are based on loss functions also have some weak points. For

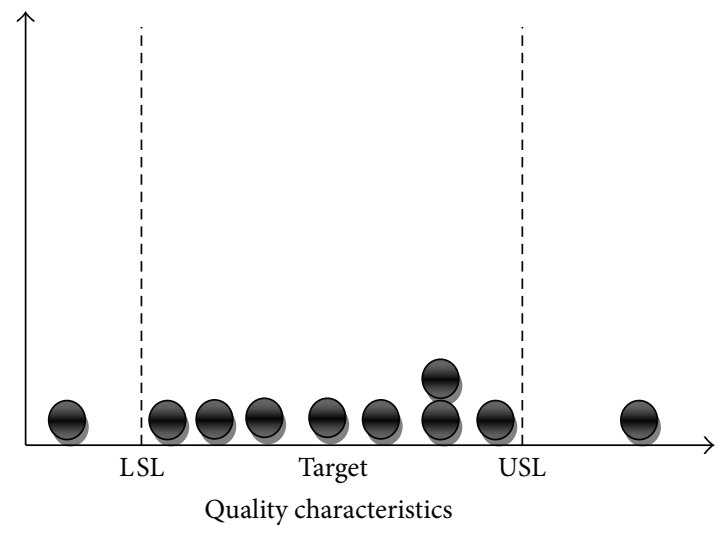

FIGURE 6: Samples from process B.

example, Pi and Low [17] who used Taguchi loss function actually used the rate of rejects and assumed 3\% defective products as the standard rate of rejects. Moreover, in the methodology of Teeravaraprug [19], Taguchi loss functions were used for just weighting the different rates, and again in order to calculate the quality, just rate of rejects, assumed.

\section{Conclusion and Suggestions for Future Research}

There are many supplier selection methods based on different criteria that were employed for solving the supplier selection problems. This paper presented a review of decision criteria reported in the literature for supporting the supplier selection process. The review was based on an extensive search in the academic literature. Therefore, all different criteria related to supplier selection were reviewed.

Quality is the most important criteria for supplier selection [6]. The methods for assessing the quality can be divided to two main categories: qualitative methods and quantitative methods. In this paper it was shown that all qualitative methods and quantitative methods can evaluate just one aspect of an organization, but cannot evaluate the whole production process; they are not suitable methods for assessing the quality of a process. Therefore, these methods have some weak points and are not appropriate tools to assess the quality. In fact, the objective functions of these methods are not realistic objects.

The suggestion of this paper for quality evaluation is the use of loss functions. Among the numerous methods that have been proposed for assessing the supplier, loss functions such as Taguchi loss function without any range are considered one of the most effective techniques for identifying quality parts. Quality loss functions are more reliable and precise functions in order to assess the quality. There are few studies such as Teeravaraprug [19] and Pi and Low [17] that used loss functions in order to evaluate the quality, but actually they have used some definitions such as weighting or ranges. This study proposes the use of loss functions without any range and weight in order to evaluate the quality of the suppliers. 


\section{References}

[1] R. M. Monczka, R. Trent, and R. Handfield, Purchasing and Supply Chain Management, International Thomson publishing, 1998.

[2] C. P. Roa and G. E. Kiser, "Educational buyer's perception of vendor attributes," Journal of Purchasing Material Management, vol. 16, pp. 25-30, 1980.

[3] L. Ellram, "The supplier selection decision in strategic partnerships," Journal of Purchasing Material Management, vol. 26, no. 4, pp. 8-14, 1990.

[4] C. L. Stamm and D. Y. Golhar, "JIT purchasing attribute classification and literature review," Production Planning \& Control, vol. 4, no. 3, pp. 273-282, 1993.

[5] C. A. Weber, J. R. Current, and W. C. Benton, "Vendor selection criteria and methods," European Journal of Operational Research, vol. 50, no. 1, pp. 2-18, 1991.

[6] G. W. Dickson, "An analysis of vendor selection: systems and decisions," Journal of Purchasing, vol. 1, pp. 5-17, 1966.

[7] R. J. Linn, F. Tsung, and L. W. C. Ellis, "Supplier selection based on process capability and price analysis," Quality Engineering, vol. 18, no. 2, pp. 123-129, 2006.

[8] S. H. Ha and R. Krishnan, "A hybrid approach to supplier selection for the maintenance of a competitive supply chain," Expert Systems with Applications, vol. 34, no. 2, pp. 1303-1311, 2008.

[9] N. Aissaoui, M. Haouari, and E. Hassini, "Supplier selection and order lot sizing modeling: a review," Computers \& Operations Research, vol. 34, no. 12, pp. 3516-3540, 2007.

[10] Y. Wind, P. E. Green, and P. J. Robinson, "The determinants of vendor selection: the evaluation function approach," Journal of Purchasing, vol. 4, no. 3, pp. 29-42, 1968.

[11] D. R. Lehmann and J. O'Shaughnessy, "Difference in attribute importance for different industrial products," Journal of Marketing, vol. 38, no. 2, pp. 36-42, 1974.

[12] W. D. Perreault and F. A. Russ, "Physical distribution service in industrial purchase decisions," Journal of Marketing, vol. 40, no. 1, pp. 3-10, 1976.

[13] R. Abratt, "Industrial buying in high-tech markets," Industrial Marketing Management, vol. 15, no. 4, pp. 293-298, 1986.

[14] T. J. Billesbach, A. Harrison, and S. Croom-Morgan, "Supplier performance measures and practices in JIT companies in the US and UK," International Journal of Purchasing and Materials Management, vol. 21, no. 4, pp. 24-28, 1991.

[15] H. Min and W. P. Galle, "Electronic commerce usage in business-to-business purchasing," International Journal of Operations \& Production Management, vol. 19, no. 9, pp. 909-921, 1999.

[16] N. Stavropolous, "Suppliers in the new economy," Telecommunication Journal of Australia, vol. 50, no. 4, pp. 27-29, 2000.

[17] W. N. Pi and C. Low, "Supplier evaluation and selection using Taguchi loss functions," International Journal of Advanced Manufacturing Technology, vol. 26, no. 1-2, pp. 155-160, 2005.

[18] W. N. Pi and C. Low, "Supplier evaluation and selection via Taguchi loss functions and an AHP," International Journal of Advanced Manufacturing Technology, vol. 27, no. 5-6, pp. 625630, 2006.

[19] J. Teeravaraprug, "Outsourcing and vendor selection model based on Taguchi loss function," Songklanakarin Journal of Science and Technology, vol. 30, no. 4, pp. 523-530, 2008.

[20] A. Sanayei, S. Farid Mousavi, M. R. Abdi, and A. Mohaghar, "An integrated group decision-making process for supplier selection and order allocation using multi-attribute utility theory and linear programming," Journal of the Franklin Institute, vol. 345, no. 7, pp. 731-747, 2008.

[21] P. Parthiban, H. A. Zubar, and C. P. Garge, "A multi criteria decision making approach for suppliers selection," Procedia Engineering, vol. 38, pp. 2312-2328, 2012.

[22] J. Peng, "Selection of logistics outsourcing service suppliers based on AHP," Energy Procedia, vol. 17, pp. 595-601, 2012.

[23] M. E. Bilişik, N. Çağlar, and O. N. A. Bilişik, "A comparative performance analyze model and supplier positioning in performance maps for supplier selection and evaluation," ProcediaSocial and Behavioral Sciences, vol. 58, pp. 1434-1442, 2012.

[24] A. Tektas and A. Aytekin, "Supplier selection in the international environment: a comparative case of a Turkish and an Australian company," IBIMA Business Review, vol. 2011, Article ID 598845, 14 pages, 2011.

[25] C.-N. Li, "Supplier selection project using an integrated Delphi, AHP and Taguchi loss function," ProbStat Forum, vol. 3, pp. 118134, 2010.

[26] O. Betül, H. Başlıgil, and N. Şahin, "Supplier selection using analytic hierarchy process: an application from Turkey," in Proceedings of the World Congress on Engineering (WCE '11), vol. 2, London, UK, July 2011.

[27] G. Mehralian, A. Rajabzadeh Ghatari, H. Morakabzti, and H. Vatanpour, "Developing a suitable model for supplier selection based on supply chain risks: an empirical study from Iranian pharmaceutical companies," Iranian Journal of Pharmaceutical Research, vol. 11, no. 1, pp. 209-219, 2012.

[28] I. A. Holjevac, "Business ethics in tourism-as a dimension of TQM," Total Quality Management and Business Excellence, vol. 19, no. 10, pp. 1029-1041, 2008.

[29] Q. E. Wang and X. M. Guo, "A study of supplier selection and quality strategy based on quality costs theory," in International Conference on Management Science and Engineering (ICMSE '07), pp. 838-843, August 2007.

[30] A. Kokangul and Z. Susuz, "Integrated analytical hierarch process and mathematical programming to supplier selection problem with quantity discount," Applied Mathematical Modelling, vol. 33, no. 3, pp. 1417-1429, 2009.

[31] A. H. I. Lee, "A fuzzy supplier selection model with the consideration of benefits, opportunities, costs and risks," Expert Systems with Applications, vol. 36, no. 2, pp. 2879-2893, 2009.

[32] S. G. Teng and H. Jaramillo, "A model for evaluation and selection of suppliers in global textile and apparel supply chains," International Journal of Physical Distribution and Logistics Management, vol. 35, no. 7, pp. 503-523, 2005.

[33] J. Hou and D. Su, "EJB-MVC oriented supplier selection system for mass customization," Journal of Manufacturing Technology Management, vol. 18, no. 1, pp. 54-71, 2007.

[34] W. Xia and Z. Wu, "Supplier selection with multiple criteria in volume discount environments," Omega, vol. 35, no. 5, pp. 494504, 2007.

[35] S. T. Tseng and T. Y. Wu, "Selecting the best manufacturing process," Journal of Quality Technology, vol. 23, pp. 53-62, 1991.

[36] Y. M. Chou, "Selecting a better supplier by testing process capability indices," Quality Engineering, vol. 6, no. 3, pp. 427438, 1994.

[37] W. L. Pearn, C. W. Wu, and H. C. Lin, "Procedure for supplier selection based on Cpm applied to super twisted nematic liquid crystal display processes," International Journal of Production Research, vol. 42, no. 13, pp. 2719-2734, 2004. 
[38] W. L. Pearn and S. Kotz, Encyclopedia and Handbook of Process Capability Indices, a Comprehensive Exposition of Quality Control Measures, George Washington University, Washington, DC, USA, 2006

[39] H. M. Zhu, "Supplier selection using process capability and price information chart," in International Conference on Wireless Communications, Networking and Mobile Computing (WiCOM '07), pp. 4850-4853, September 2007.

[40] F. H. F. Liu and H. L. Hai, "The voting analytic hierarchy process method for selecting supplier," International Journal of Production Economics, vol. 97, no. 3, pp. 308-317, 2005.

[41] J. M. Juran, A History of Managing for Quality: The Evolution, Trends, and Future Directions of Managing for Quality, ASQC Quality Press, Milwaukee, Wis, USA, 1995.

[42] G. Taguchi, introduction to Quality Engineering: Designing Quality in to Products and Processes, Asian Productivity Organization, Tokyo, Japan, 1986.

[43] B. Ramakrishnan, P. Sandborn, and M. Pecht, "Process capability indices and product reliability," Microelectronics Reliability, vol. 41, no. 12, pp. 2067-2070, 2001.

[44] C. W. Reimann and H. S. Hertz, "The Baldrige Award and ISO 9000 registration compared," Journal for Quality and Participation, vol. 19, pp. 12-19, 1996.

[45] A. Adamyan and D. He, "Analysis of sequential failures for assessment of reliability and safety of manufacturing systems," Reliability Engineering and System Safety, vol. 76, no. 3, pp. 227236, 2002.

[46] M. Perakis and E. Xekalaki, "A process capability index that is based on the proportion of conformance," Journal of Statistical Computation and Simulation, vol. 72, no. 9, pp. 707-718, 2002. 

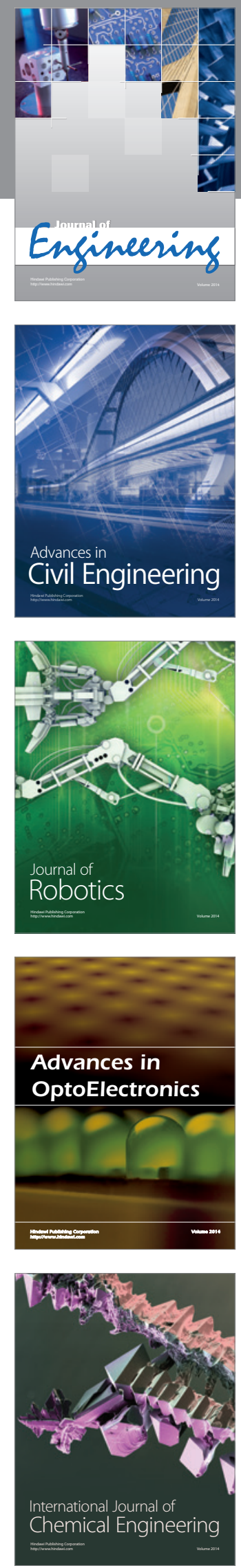

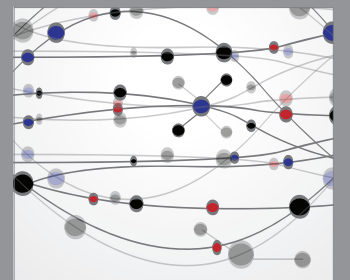

The Scientific World Journal
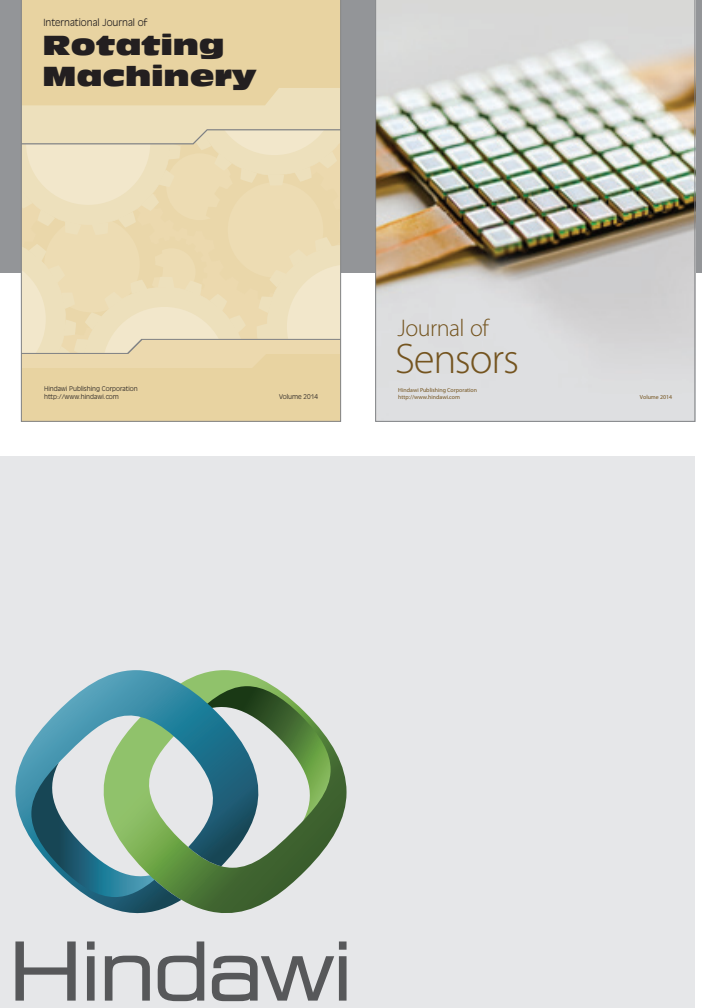

Submit your manuscripts at http://www.hindawi.com
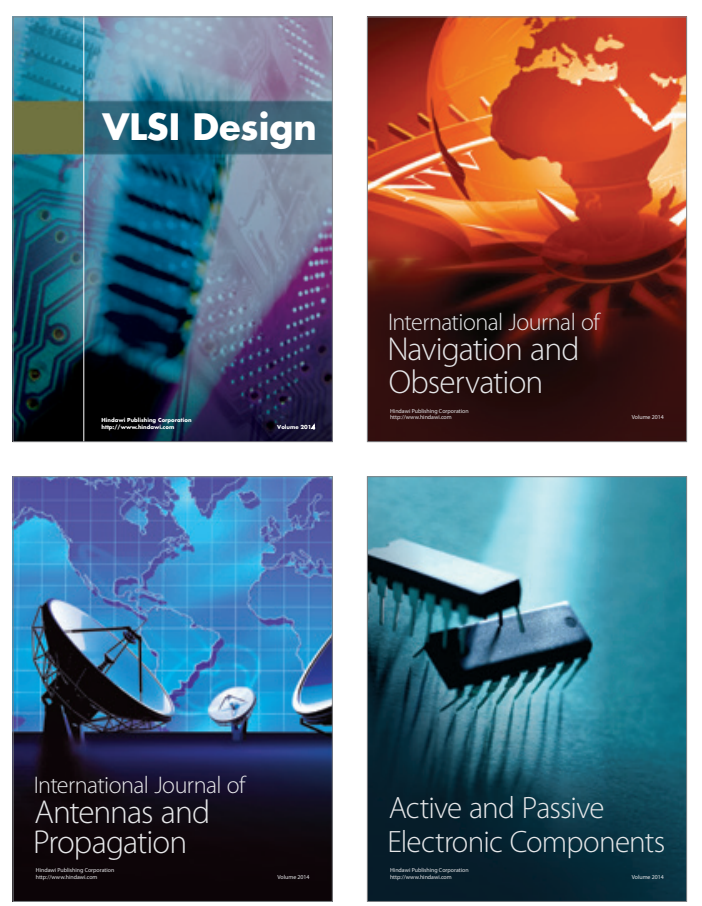
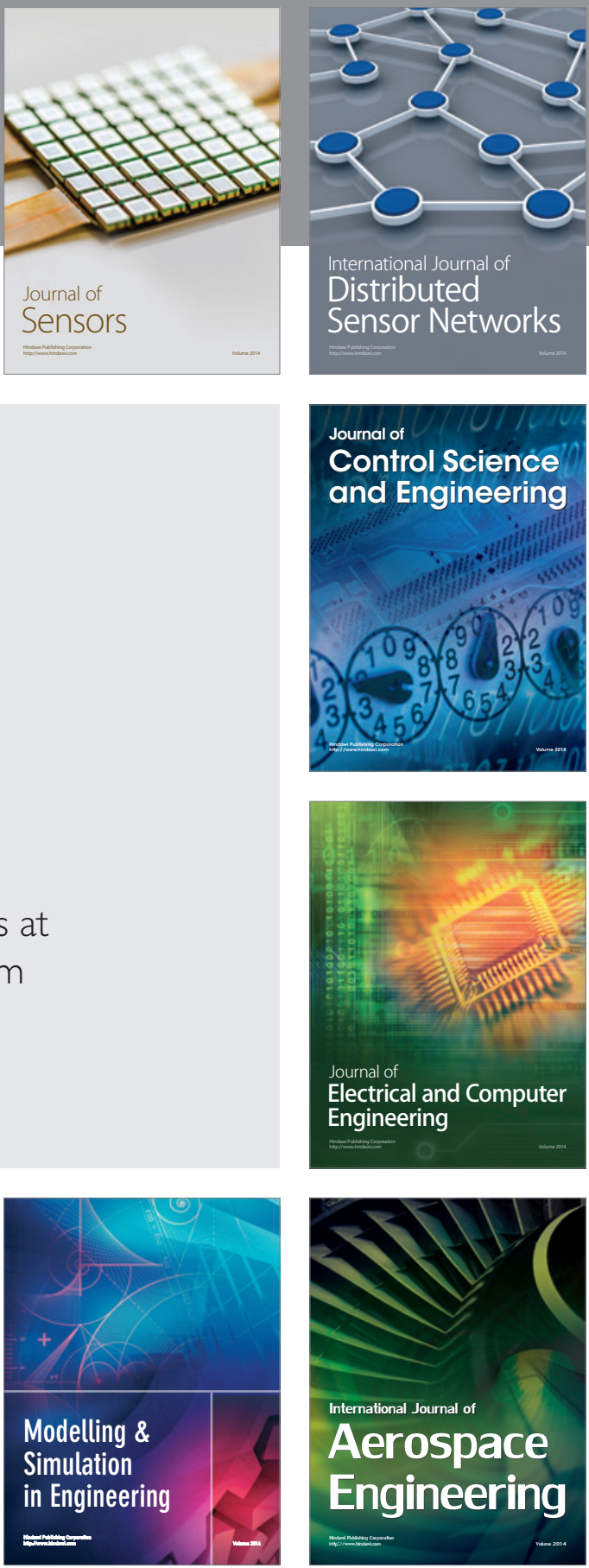

Journal of

Control Science

and Engineering
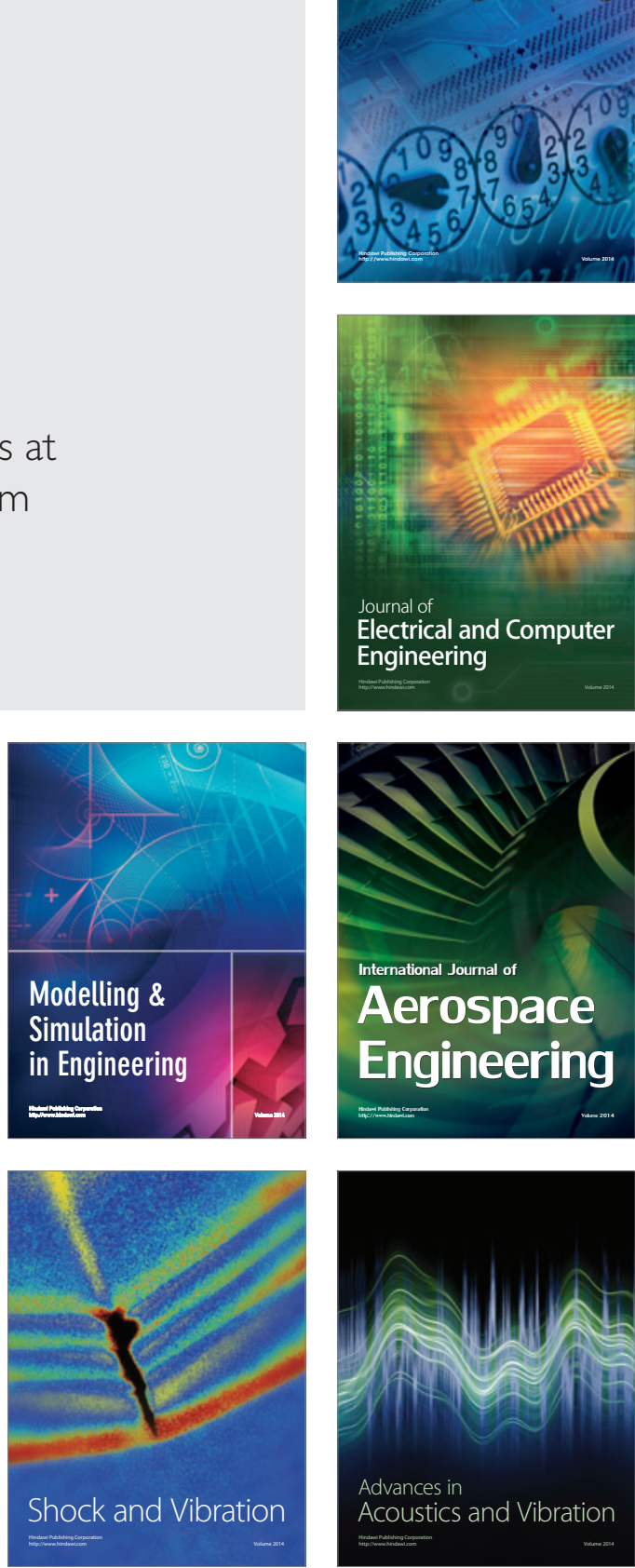